\title{
Investigation of milking equipment cleaning procedures in three geographical areas where milk chemical residues were identified in bulk milk
}

D Gleeson, B O'Brien

Teagasc, Dairy production Research centre, Moorepark, Fermoy, Co. Cork., Ireland Email: david.gleeson@teagasc.ie

Introduction Milk consumers and regulatory agencies demand that milk be free of harmful adulterants. Excessive residues may be a cause for concern for human health, export regulations for dairy products or interference with the manufacturing process. Inappropriate equipment cleaning procedures can increase milk bacterial levels and can cause chemical residues in milk. The objective of this study was to identify inappropriate equipment cleaning practises which may account for the high chemical residues found in bulk tank milk and to establish if the farm management practises identified differed depending on the processor location.

Material and methods Individual milk suppliers were identified from three milk processors in different geographical locations $(A(n=17), B(n=14)$ and $C(n=14))$ with bulk milk showing higher than acceptable milk residue levels. These farms were visited and the cleaning procedures investigated. A questionnaire survey (39 questions) was conducted to establish the cleaning practises for both the milking machine and the bulk tank on these farms. Management practises which were considered likely to result in milk residues and which did not conform to those as recommended by Teagasc (O'Brien, 2008) were considered unsatisfactory. Samples of the farm mains water supply was tested on site for the presence of available chlorine. Data was analysed using the Chi-square test to identify any relationships between processor location and management practises.

Results Unsatisfactory milking equipment cleaning practises were observed on each farm visited and the occurrence of some management practises differed depending on the geographical area (Table 1). Re-using of the post-detergent rinse water as a post-milking rinse (prior to detergent wash) at the subsequent milking was more likely to occur at location A $(\mathrm{P}<0.05)$. Detergent wash solvent is recommended to be reused only on one occasion; however this solvent was re-used more than once at all three locations. A higher proportion of farms at locations $\mathrm{A}$ and $\mathrm{C}$ did not use sufficient rinse water to remove the detergent solvent compared to farms at location $\mathrm{B}(\mathrm{P}<0.05)$. Insufficient rinse water usage was influenced by trough size, price of water (group schemes), short wash cycles in bulk milk tanks and a lack of knowledge of the importance of using sufficient water. In-correct levels of detergent tended to be used at locations $\mathrm{B}$ and $\mathrm{C}$ compared to location $\mathrm{A}(\mathrm{P}<0.06)$, due mainly to a lack of measuring equipment. Using the incorrect chemicals for cleaning either the bulk tank or milking machine occurred more often at locations $\mathrm{A}$ and $\mathrm{B}$ compared to location $\mathrm{C}(\mathrm{P}<0.01)$. A further unsatisfactory cleaning practise observed at all locations was the practise of not rinsing the detergent steriliser product from the plant immediately after the main wash cycle. Proportionally (0.94) of farms at location A had public group water supplies while (0.92) of farms at locations B and (0.67) at location C used a private well water source. The public water supply contained acceptable levels of available chlorine $(0.2$ to $0.8 \mathrm{mg} / \mathrm{l})$. Thus, the presence of chlorine in this water at the levels recorded may only be a factor if the detergent solvents were not used as recommended. Machine installation in some instances can hinder successful cleaning of equipment by not allowing complete draining of equipment between each wash cycle. Proportionally (0.71) and (0.29) of milking machines visited had milk recorder jars and pipeline milking systems fitted. The higher proportion of these problem farms had recorder jars which may indicate that using sufficient rinse water is more critical with this milking system. The bulk milk tank was identified as being the main equipment source of the residue problem at location $\mathrm{B}(0.67)$ whereas the milking machine was considered the main equipment source at locations $\mathrm{B}(0.46)$ and $\mathrm{C}(0.46)$. While other factors may influence high chemical residues in milk the faults outlined were considered the likely factors influencing the residue levels observed on these farms.

Table 1 Proportion of farms with cleaning procedure faults at three processor locations

\begin{tabular}{lllll}
\hline & Location & & & \\
Main cleaning faults observed & $\mathrm{A}(\mathrm{n}=17)$ & $\mathrm{B}(\mathrm{n}=14)$ & $\mathrm{C}(\mathrm{n}=14)$ & Significance \\
\hline Re-using the post-detergent rinse water & 0.06 & 0.00 & 0.01 & $\mathrm{P}<0.05$ \\
Using chemicals in post milk rinse & 0.00 & 0.01 & 0.01 & $\mathrm{n} . \mathrm{s}$ \\
Re-using detergent solvent $>$ once & 0.03 & 0.04 & 0.07 & $\mathrm{n} . \mathrm{s}$ \\
In-sufficient rinse water for the milking machine & 0.13 & 0.06 & 0.13 & $\mathrm{P}<0.05$ \\
Chemical products used for wrong task & 0.09 & 0.08 & 0.01 & $\mathrm{P}<0.01$ \\
Incorrect levels of chemical used & 0.01 & 0.05 & 0.05 & 0.06 \\
Incorrect operation of cleaning system & 0.04 & 0.02 & 0.01 & $\mathrm{n} . \mathrm{s}$ \\
Machine installation fault & 0.02 & 0.01 & 0.02 & $\mathrm{n} . \mathrm{s}$ \\
\hline \hline
\end{tabular}

Conclusion Unsatisfactory management practises in relation to the cleaning of milking equipment were observed on all farms and the occurrence of some individual faults differed between locations. It may be speculated that the factors influencing chemical residues in milk may be due to a single or multiple incorrect equipment cleaning practises. The factors highlighted from this investigation may be used as a template when solving chemical residue issues on farms in general.

\section{References}

O’Brien, B. 2008. Teagasc, Milk Quality Handbook. 8, 1-104. 